\title{
A filosofia hermenêutica heideggeriana - possibilidades para uma melhor compreensão do direito civil
}

\author{
Heideggerian hermeneutic philosophy - possibilities for a better \\ understanding of civil law
}

Luiz Augusto Castello Branco de Lacerda Marca da Rocha

augustocastellobranco@gmail.com

(Centro Universitário Augusto Motta - UNISUAM, Rio de Janeiro, Brasil)

\begin{abstract}
Resumo: 0 presente trabalho se propõe a avaliar as bases do pensamento filosófico de Martin Heidegger, e como sua filosofia hermenêutica (posteriormente complementada pela hermenêutica filosófica de Gadamer) pode contribuir para uma reestruturação do discurso jurídico, libertando o jurista da lógica mecanicista que aprisiona seu pensamento. Será analisada em particular sua aplicabilidade ao Direito Civil, especialmente no tocante às relações jurídicas existenciais, nas quais a superação da lógica sujeito-objeto para uma relação sujeito-sujeito pode aparatar o jurista com novos instrumentos, úteis para a reflexão e o enfrentamento de situações concretas.
\end{abstract}

Palavras-chave: hermenêutica; diferença ontológica; círculo hermenêutico; dignidade; personalidade.

\begin{abstract}
This work aims to evaluate the bases of Martin Heidegger's philosophical thought, and how his hermeneutic philosophy (later complemented by Gadamer's philosophical hermeneutics) can contribute to a restructuring of the legal discourse, freeing the jurist from the mechanistic logic that imprisons his thought. In particular, its applicability to Civil Law will be analyzed, especially with regard to existential legal relations, in which the overcoming of the subject-object logic for a subject-subject relationship can equip the jurist with new instruments, useful for reflection and facing concrete situations.
\end{abstract}

Keywords: hermeneutics; ontological difference; hermeneutic circle; dignity; personality.

DOI: http://dx.doi.org/10.11606/issn.2318-9800.v25i4p209-218

\section{Introdução}

A pós-modernidade - e as inovações por ela trazidas - impõem sensíveis desafios ao jurista dos tempos atuais. O aumento do fluxo de pessoas - muitas das vezes causado pela busca por condições mínimas de vida digna -, a questão ambiental - a envolver as gerações presentes e futuras -, a virtualização das relações humanas com o ciberespaço como novo lócus de relações negociais e afetivas - são alguns dos exemplos desses desafios, para os quais o jurista não encontra respostas satisfatórias.

Especificamente no campo do direito civil, essa metamorfose (termo empregado por Ulrich Beck (2018, p. 15), como um conceito sociológico inédito - e inacabado, distinto das noções já consolidadas de mudança, revolução ou transformação, a significar "uma radical reestruturação das bases sociais, com a revisão das visões 
tradicionais de mundo, como efeitos colaterais de fenômenos característicos da modernização, nem sempre apreensíveis racionalmente") tem afetado de modo substancial seus institutos clássicos - família, propriedade, contrato -, historicamente estruturados por um viés voluntarista-patrimonialista. Questões atuais e sensíveis surgem a todo instante, levando o estudioso e o aplicador do direito a constantemente questionar as bases em que se estrutura o conhecimento jurídico. As novas entidades familiares - multiparentalidade, coparentalidade, poliamorismo, família paralela e interespécies - escapam a concepções pré-estabelecidas de família, pautadas em valores sociais fortemente enraizados e externos ao núcleo constituído. A filiação se reinventa, com a gestação de substituição e as surrogate mothers lançando a dúvida sobre a (até então) mais consolidada certeza das relações sociais, insculpida no brocardo mater semper certa est. Debates sobre o início da vida e da personalidade ganham nova amplitude quando a natureza dos embriões excedentários é posta em questão. A própria concepção de pessoa é revisitada para buscar uma nova extensão quando a "tirania confortável" de entender os animais como "bens semoventes" começa a ser abandonada em prol de uma visão que os compreende como "pessoas não humanas" (ou, ao menos, como seres "sencientes"). Os direitos da personalidade, em sua ebulição constante, também são rico manancial para essa "perplexidade do jurista": pessoas realizam procedimentos destinados a alterar radicalmente seus corpos, de modo a expressar sua identidade; ${ }^{1}$ o direito ao esquecimento e à identidade virtual são reclamados e ao mesmo tempo em que os "dados sensíveis" têm sua importância reconhecida, a intimidade se expõe e desnuda, projetando-se para o cibermundo, convertida em "extimidade" 3 .

A metodologia do direito-civil constitucional, popularizada no Brasil, pelas contribuições, dentre outros, de Gustavo Tepedino (2004), Maria Celina Bodin de Moraes (1991) e Luiz Edson Fachin (2012) representou inegáveis avanços ao apresentar a proposta - hoje universalmente aceita - de sua releitura com base nos valores irradiantes da Constituição Federal, dentre os quais o reconhecimento, tutela e promoção da dignidade humana, conferindo maior valoração às relações existenciais, impondo o "primado do ter sobre o ser".

Se o progresso representado por essa nova diretriz é inquestionável, urge, ainda assim, dar um passo adiante. Na medida em que as relações existenciais são erguidas à posição de superioridade, o problema da "existência" e do "ser" é trazido ao foco central do discurso jurídico. Ciente desse desafio, este trabalho pretende discutir a

10 fenômeno conhecido como body modification e, em escala mais dramática, os denominados amputee by choice.

2 A expressão foi cunhada pelo civilista italiano Stefano Rodotà $(2008$, p. 119) para se referir a certa categoria de dados que, por envolverem especial potencial discriminatório (e.g., orientação sexual, afiliação política, estado de saúde) compõem o núcleo da privacidade, conceituada por ele como "autodeterminação informativa".

30 neologismo foi criado por Paula Sibillia (2016, p. 115), para se referir ao fenômeno das personalidades alterdirigidas, característico de uma cultura de hiperexposição, marcante nos dias atuais. 
A filosofia hermenêutica heideggeriana - possibilidades para uma melhor compreensão ...

filosofia hermenêutica de Martin Heidegger, investigando como seu construto pode auxiliar o jurista em sua tarefa de responder às demandas com as quais se confronta diuturnamente, proporcionando uma melhor compreensão da realidade que o cerca e fornecendo critérios hermenêuticos mais seguros a esta empreitada.

\section{Heidegger e a destruição da metafísica}

0 construto intelectual de Heidegger representa uma ruptura com o pensamento até então existente, realizando "uma mudança de paradigma na filosofia" (Stein, 2014, p. 16). O entendimento dessa assertiva pressupõe uma abordagem prévia do caminho trilhado até sua obra emblemática, Ser e Tempo.

A filosofia pré-heideggeriana, em especial a história da metafísica ocidental, sempre buscou explicar as questões correlatas à ontologia e à verdade a partir do recurso a Deus e/ou à natureza (idem, ibidem), elementos externos ao ser. Esta representação, contudo, por operar no plano da relação sujeito-objeto, apresenta um inconveniente, conduzindo ao encobrimento do ser pelo ente na história da metafísica ocidental, cujo ponto culminante teria se dado na modernidade - sendo possível citar, a título ilustrativo, a "substância" ou ousia, no pensamento aristotélico, o cogito cartesiano, o “eu penso" em Kant, o "eu absoluto" em Hegel e a “vontade de poder”, em Nietzsche (Trindade, 2017, p. 194). Heidegger rejeita este duplo fundamento, promovendo um "encurtamento" da ontologia (Stein, 2014, p.23), para “libertá-la” da necessidade de uma explicação teológica (Heidegger, 2015, p. 301), ou pautada e um determinismo das leis naturais. ${ }^{4}$ Seu ineditismo consiste na elaboração de um projeto filosófico-fenomenológico voltado para a questão da essência (sentido) do ser, indagando por suas condições transcendentais fora da representação, produzindo seu desvelamento e, desse modo, "transformando os conceitos de ontologia, de hermenêutica e de fenomenologia, introduzindo a facticidade como um novo campo de investigação" (Trindade, 2017, p. 192-193).

Dentro do pensamento heideggeriano, é de fundamental relevo recorrer aos teoremas da diferença ontológica e do círculo hermenêutico.

Por diferença ontológica, se entende a dissociação entre ser e ente. 0 ser - nível ontológico, ek-xistência - é fluído e anterior, constituindo condição de possibilidade para a compreensão do ente - nível ôntico, existência (Inwood, 2002, p. 42) -, sendo indefinível, sob pena de se ver reduzido a este (Mello, 2018a, p.27). Sua determinabilidade (relativa) se dá somente em relação a uma temporalidade

\footnotetext{
4 Heidegger utiliza o exemplo das Leis de Newton que só são uma vez que formuladas por um "estará" para demonstrar que o ente revelado só o pôde ser em função da presença que o antecede. "As leis de Newton, antes dele, não eram verdadeiras nem falsas. Isso não pode significar que o ente que elas, descobrindo, demonstram não existisse antes delas. As leis se tornam verdadeiras com Newton. Com elas, o ente em si mesmo se tornou acessível à presença. Com a descoberta dos entes, estes se mostram justamente como os entes que já eram antes delas. Descobrir, assim, é o modo de ser da 'verdade'” (Heidegger, 2015, p. 298).
} 
específica (Casanova, 2015, p. 77). Tem-se, então, um ente privilegiado, o “seraí" (Dasein), essencial à obra do filósofo. O fundamento do Dasein é sem fundo, abissal (Ab-Grund) (Mello, 2015, p. 45), dado que apenas o ente é respectivamente fundamentado (idem, p. 53). Tal assertiva não implica afirmar que seja irracional ou arbitrário, mas antes não vinculado a um atributo específico, como a razão ${ }^{5}$ e, nisso, Heidegger se afasta, dentre outros, de Kant, uma vez que este, ao formular sua teoria moral sobre a dignidade humana a associa à capacidade racional de formular imperativos categóricos universalmente válidos. Esta percepção é relevante porque a ideia de dignidade, fundamento das relações existenciais que constituem o core do direito civil, é tradicionalmente abordada, em doutrina pátria, sob um prisma kantiano. A busca por uma clareza em relação ao ser do Dasein é considerada um pré-requisito para lidar com a questão do sentido do ser enquanto tal e sua análise passa a ser denominada ontologia fundamental (Gorner, 2018, n.p.).

O teorema da circularidade hermenêutica é outra significativa contribuição de Heidegger. Por intermédio dele, o filósofo afasta a hermenêutica de seu sentido originário de "arte de interpretar" (Pereira, 2015, p. 159) para o de teoria filosófica, tal qual já o fizera Dilthey anteriormente, introduzindo seu caráter histórico e afastando-a do princípio da causalidade (idem, p. 161). Em que pese ter sido confessadamente influenciado por Dilthey, Heidegger dele se afasta (Heidegger, 2015, p. 91), na medida em que seu interesse por ela é mais ontológico - como um modo de pensar "originariamente" a fenomenologia - do que epistemológico/metodológico (Mora, 2001, p. 332). Em Heidegger, a hermenêutica tem função meramente adjetiva, até certo ponto secundária, cuja finalidade é explicitar a facticidade como elemento constitutivo do Dasein, atuando como um compreender prévio (pré-compreender) do seu modo de ser (Trindade, 2017, p. 193), passando a adquirir um caráter mais substancial posteriormente, no pensamento de Gadamer - cujo objetivo era discutir a universalidade do problema da interpretação (idem, p. 199; Pereira, 2015, p. 166). Todo esse processo - que somente é possível por meio de uma dimensão histórica (historicidade), posta através da linguagem (fenômeno cultural e, até certo ponto, intuitiva) (Fachin, 2011, p. 190) - possui uma “estrutura circular”, pela qual o reconhecimento do que algo é pressupõe uma prévia compreensão que, devendo ser autêntica e existencial, pertence à estrutura do sentido que só se torna possível ao

\footnotetext{
5 "Ele não localiza a essência do homem em alguma faculdade específica tal como a razão: um dos aspectos centrais de Dasein, junto com o SER-LAN-ÇADO e a DECADÊNCIA, é a EXISTÊNCIA, e isto significa que ele tem de decidir como ser. Isso significa que Dasein não é essencialmente e inevitavelmente racional. Já que Dasein existe e não é um SER-SIMPLESMENTE-DADO, não cabe perguntar 'o que' ele é; deveríamos perguntar 'quem' ele é, e a resposta dependerá de, e até mesmo consistirá na, decisão de Dasein: pode ser 'eu mesmo' ou pode ser 'o ninguém a quem todo Dasein já se rendeu ao ser em meio aos outros' (ST, 128; cf. ST, 45; XXXIV, 57s): 'Tudo em que alguém constantemente toma parte, pratica [ex., ensinar], determina o que ele é [ex., um professor). Mas se sabemos o que somos, será que sabemos consequentemente quem somos? Não'” (Inwood, 2002, p. 30)).
} 
entender sua própria facticidade (Streck, 2014, n.p.). A compreensão surge, assim, como uma abertura do ser-no-mundo, além de um existencial que, como clareira (Alethéia), sempre se desvela, a medida em que é buscada (Mello, 2018a, p. 27-28).

Diferença ontológica e círculo hermenêutico constituem pilares da fenomenologia heideggeriana (Mello, 2018b, p.34) que seriam posteriormente desenvolvidos em Gadamer. Tecidas algumas considerações elementares a respeito da ontologia fundamental, se passa a uma tentativa de aplicação às relações existenciais do direito privado.

\section{Algumas reflexões sobre a aplicabilidade da ontologia fundamental ao direito civil}

Um retorno à dignidade parece fornecer um caminho promissor. Conforme visto, Heidegger se afasta de Kant, na medida em que sua explicação da essência do ser prescinde da referência a atributos específicos, advenham estes de origem natural ou teológica (o ser-no-mundo). Para o filósofo de Königsberg, a ideia de dignidade, compreendida enquanto qualidade humana que impede sua objetificação, pressupõe a razão como qualidade comum e compartilhada pela humanidade. Tal racionalidade, insista-se, seria o fator que permitiria ao homem (em sua condição humana, não enquanto gênero) formular a lei moral, universalmente válida, na medida em que passível de ser seguida por todos, sem contradições.

A concepção kantiana de dignidade é tradicionalmente evocada (e frequentemente banalizada) pela doutrina e jurisprudência pátrias. 0 recorte kantiano, contudo, não explicaria problemas importantes, como o tratamento dado ao nascituro (e, indo mais além, ao concepturo), ou ligados à terminalidade da vida e a morte digna (como a eutanásia e o suicídio assistido), ou mesmo relacionados a comportamentos não racionais, decorrentes de impulsos passionais, intencionalmente assumidos. Nesse sentido, essa rigidez abstrata quase ficcional presente na visão kantiana de dignidade ao valorizar somente a racionalidade é objeto de críticas por sua pouca compatibilidade com o indivíduo real e passível de paixões e impulsos (Sarmento, 2016, p. 43).

Ademais, a autonomia racional kantiana foi (algo indevidamente) apropriada pelo pensamento liberal-burguês típico das codificações oitocentistas, em uma concepção de indivíduo abstrato estereotipado - branco, proprietário e do sexo masculino - pautado por escolhas de racionalidade econômica estrita. Esse verdadeiro homo economicus foi duramente criticado por Stefano Rodotà, para quem a transposição "do sujeito (abstrato) à pessoa (concreta)"6 seria uma virada necessária para uma correta compreensão dos direitos ligados às situações jurídicas existenciais

6 No mesmo sentido, cf. Filho, 2008, p. 310. 
dentro de ordenamentos estruturados na tutela da dignidade. ${ }^{7}$ Para tanto, para a busca por essa "dignidade real" envolve uma compreensão do ser humano com base em suas particularidades concretas (Mello; Martins, 2016, p. 1.448), em seu modo de ser-no-mundo, a exigir do jurista uma nova hermenêutica concretizadora (Mello, 2014, p. 43). ${ }^{8}$ Nessa perspectiva, a dignidade é reconhecida em seu caráter metajurídico, transcendendo o plano jurídico para preexistir a ele não podendo, portanto, ser reduzida ao papel de parâmetro para verificação de validade da norma jurídica, antes constituindo o próprio sentido do ser, "É, pois, o Dasein como serno-mundo, como pressuposto de qualquer teoria do conhecimento ou fenômeno jurídico" (Mello; Martins, 2016, p.1.448).

As ideias de historicidade e tradição, conceitos trabalhados em Gadamer, também são extremamente relevantes para uma adequada interpretação do direito. A compreensão da pessoa em seu acontecer historicamente situado permite a necessária abertura do direito a suas possibilidades emancipatórias (Mello, 2014, p. 44). Esse conscientizar conduz o jurista a uma "ruptura" com uma lógica objetificadora, de caráter meramente reprodutivo, incapaz de atender a realidade que se descortina diante de seus olhos o que, de certo modo, implicaria em negar a própria ciência jurídica (Fachin, 2011, p. 198-199). Basta pensar nos conceitos jurídicos indeterminados e nas cláusulas gerais que permeiam o ordenamento. "Bons costumes", "função social", "boa fé" exigem o ultrapassamento da estrita normatividade e um esforço hermenêutico que não os distancie da realidade pela sedução da teorização abstrata. Tome-se ainda o exemplo do direito de família, agrilhoado a normas restritivas de suas possibilidades, encapsulado em um positivismo reducionista. Esta consciência da historicidade proporcionada pela filosofia hermenêutica (e pela hermenêutica filosófica gadameriana) permite assegurar uma fusão de horizontes capaz de "reatar o casamento" entre o direito e o mundo da vida, do qual se havia "divorciado" (Welter, 2009, p. 110-111), substituindo a reprodução de um status não mais justificável nos tempos atuais por uma produção de sentido do texto atualizada pela pré-compreensão que o intérprete tem do presente (idem, p. 113).

A quebra de um paradigma "sujeito-objeto" para uma visão "sujeito-sujeito" igualmente permite ao direito migrar desta abordagem que se contentava em re-alizar (entificar, reificar, coisificar), o direito objetificando-o, para um efetivo "real-izar" da pessoa em sua dignidade, buscando o resgate do homem em sua essência, como possibilidade e modo de ser no mundo (Mello, 2018b, p. 194). Esta não cabe mais no

\footnotetext{
7 Em sentido aproximado, Schreiber, Navares, 2016, p. 39.

8 Nas palavras do autor: “Ora, é a concepção do fenômeno jurídico alinhado ao mundo da vida ou mundo vivido (Ernildo Stein). É o interfaceamento do direito com a ideia de ser-no-mundo (Dasein, na concepção heideggeriana). Melhor dizendo: é a possibilidade de análise do fenômeno jurídico a partir de suas vicissitudes totalitárias concretas no mundo da vida. É a relação jurídica ajustada a uma nova dinâmica social de inter-relação humana vista a partir de suas especificidades concretizantes" (Mello, 2014, p.43).
} 
casulo do hermetismo liberal do homem isolado, bastante-em-si. Desloca-se para uma perspectiva relacional, pautada por uma lógica de alteridade, em que se ultrapassa os limites de si próprio para se entender no lugar do outro, em uma verdadeira “Hermenêutica do Tu” (Mello, 2014, p. 45). Reconhecer o outro como merecedor de igual consideração e respeito, em seu modo de ser-no-mundo, reconhecer seu direito à diferença é o novo imperativo moral deste "mundo caleidoscópio", plural, ${ }^{9}$ no qual o ser passa a ser também ser-para-o-outro. Os direitos da personalidade e o direito de família fornecem ricas ilustrações para essa assertiva.

Em relação aos direitos da personalidade, são estes o core da realização da dignidade. Mas não uma dignidade opaca, imobilizada por estritos padrões racionais, mas uma dignidade viva, pulsante, imperfeita, multifacetada que não pode ser aprisionada, "entificada" pelo normativismo rígido, em especial um tão imperfeito quanto o que the foi dedicado pelo Código Civil. A pessoa humana em suas possibilidades não se restringe a uma aplicação lógico-silogística, antes se edifica em seu e sua historicidade e sua ação no mundo. Deve, pois, ser "decodificada", desvelada, não podendo mais ser escondida sob o manto do texto legal.

Ilustremos nosso argumento com a privacidade (quiçá o mais fragilizado e ameaçado dos direitos fundamentais). Uma pré-compreensão histórica de seu significado se faz necessária para a compreensão da mesma como elemento essencial para a realização da pessoa, que não pode ser alcançada se descolada de sua historicidade, que a retirou a roupagem de mero isolamento para desvelar seu sentido de autodeterminação informativa e controle dos dados pessoais. O mesmo se pode afirmar de outros direitos da personalidade, como a integridade psicofísica, a imagem (que deixa de ser "apenas" um direito de identificação para tornar-se um veículo de expansão do ser, em uma sociedade profundamente interativa por meio de estímulos imagéticos) e o nome (quanto a este, um de seus componentes, o sobrenome, se desvela não mais como uma "cláusula de pertencimento" a um grupo familiar, continuador da linhagem, mas como um verdadeiro componente do ser, conforme se depreende de recente decisão da Justiça do Amazonas que reconheceu o direito de uma mulher que passara sua infância em um orfanato, e cujos pais eram desconhecidos, em criar um sobrenome ${ }^{10}$ ).

Por fim, retorna-se ao direito de família. Se a pessoa é o núcleo da dignidade (pré e metajurídica), a família é seu ninho. Deste modo, não pode ser compreendida como um "a priori lógico-conceitual”; ao contrário, reclama uma "abertura histórica para o mundo da vida", no qual se realizam suas infindas possibilidades (Welter, 2009, p.145). É esta abertura que permite a investigação do sentido adequado em situações que, na atualidade, demandam do aplicador do direito esse desvelamento do sentido do termo família, partindo de uma pré-compreensão reveladora que

9 Em sentido próximo, Mello, 2014, p. 45.

10 Para uma análise jurídica do caso, cf. Rocha; Almeida, 2017, p. 181-202. 
(não se prendendo aos escassos limites do positivismo legalista do "homem e mulher"), nem desconsiderando seu caminhar histórico, desvele seu alcance de modo suficientemente elástico, que permita abranger os - assim chamados no jargão jurídico - novos arranjos familiares (uniões homoafetivas, poliafetivas, famílias recompostas, famílias multiespécies e outros fenômenos encontrados na realidade fervilhante da vida).

Tomemos como exemplo o afeto, seu elemento mais basilar e essencial, justificador da tutela jurídica da família. Não é adequado que sua aplicação se dê exclusivamente com base nas percepções pessoais de mundo do julgador (o que conduziria a um criticável decisionismo subjetivista, algo aproximado da escola do "direito livre"), tampouco se limitar aos caminhos de uma normatividade abstrata. Antes se impõe um entendimento que desvele seu real sentido, partindo de uma pré-compreensão que se torne um compreender (orientado em direção ao sentido correto pela tradição) na medida em que se concretiza no mundo.

Novamente é possível ilustrar, em sede familista, com o complexo dilema envolvendo a surrogate mother e a desconstrução do brocardo mater semper certa est. A pré-compreensão do que é ser mãe é usada pelo intérprete para auxiliar a desvelar o sentido oculto do ser mãe, quando já não mais se pode reduzir o seu concretizar ao desenvolvimento do processo gestacional, havendo antes que perquirir se elementos como a vontade procriacional originária do casal que planejou o projeto parental devem ser considerados no processo decisório. A redução ao elemento genético/ gestacional não mais revela, por si, o sentido do "ser-mãe", devendo ser repensada.

As breves reflexões aqui tecidas na seara do direito privado em suas relações existenciais demonstram um pouco da contribuição que a hermenêutica filosófica pode conferir a um redimensionar do discurso jurídico.

\section{Conclusão}

Este artigo se propôs a analisar sucintamente as bases do pensamento filosófico de Martin Heidegger, contextualizando e tentando, de algum modo, aplicá-lo ao universo do direito, em particular às relações existenciais do direito privado. Embora não tenha sido um filósofo do direito, sua filosofia hermenêutica surge como uma importante contribuição, capaz de propor novos fundamentos para uma nova abordagem e compreensão do fenômeno jurídico. Diferença ontológica, circularidade hermenêutica, temporalidade, dentre outras de suas construções fornecem elementos importantes para um re-pensar, uma "reflexão disruptiva" que retire o jurista do raciocínio lógico-mecanicista característico do positivismo que ainda norteia seu pensamento, ${ }^{11}$ superando os limites impostos por sua racionalidade

11 Em sentido aproximado: "embora Heidegger jamais tenha se dedicado, ou mesmo preocupado, com o direito - sua produção teórica funda bases através das quais é possível lançar um novo olhar sobre a hermenêutica jurídica e a própria compreensão do direito, mormente se levado em consideração 
A filosofia hermenêutica heideggeriana - possibilidades para uma melhor compreensão ...

abstrata (Mello, 2018b, p. 193), abandonando a ilusória sensação de segurança em um sistema autossuficiente, capaz de proporcionar todas as respostas (Mello, 2015, p. 53). É um convite ao jurista contemporâneo para um efetivo real-izar do direito, emancipador da pessoa humana.

\section{Referências}

Beck, U. (2018). A metamorfose do mundo: novos conceitos para uma nova realidade. Tradução de Maria Luíza X. de A. Borges, revisão técnica Maria Cláudia Coelho. Rio de Janeiro, RJ: Zahar.

Casanova, M. A. (2015). Compreender Heidegger. $5^{\mathrm{a} e d . ~ P e t r o ́ p o l i s, ~ R J: ~ V o z e s . ~}$

Fachin, L. E. (2011). Aspectos de alguns pressupostos histórico-filosóficos hermenêuticos para o contemporâneo direito civil brasileiro: elementos constitucionais para uma reflexão crítica. Revista. TST, Brasília, 77 (4), 186-203. DOI: http://dx.doi.org/10.5007/2177-7055.2008v29n57p285

Fachin, L. E. (2012). Teoria Crítica do Direito Civil. $3^{\mathrm{a} e d .}$ Rio de Janeiro, Renovar.

Filho, J. C. M. (2008). A Repersonalização do Direito Civil a partir do pensamento de Charles Taylor: algumas projeções para os Direitos de Personalidade. Revista Seqüência, 29 (57), 299-322. Recuperado de: https://periodicos.ufsc.br/index.php/ sequencia/article/view/2177-7055.2008v29n57p285/13649. Acesso em: 23.05.2020.

Gorner, P. (2018). Ser e Tempo: uma chave de leitura. Tradução de Marco Antônio Casanova. Petrópolis, RJ: Vozes.

Heidegger, M. (2015). Ser e Tempo. Tradução de Márcia de Sá Cavalcante. $10^{a}$ ed. Petrópolis, RJ: Vozes.

Inwood, M. (2002). Dicionário HEIDEGGER. Tradução de Luísa Buarque de Holanda. Rio de Janeiro, RJ: Jorge Zahar.

Mello, C. M. (2014). Hermenêutica Filosófica de Heidegger. Revista Ética e Filosofia Política, II (XVII,), 41-54. Recuperado de: http://www.ufjf.br/eticaefilosofia/ files/2009/08/17_2_mello.pdf. Acesso em: 22.05.2020.

Mello, C. M. (2015). O Fundamento do Direito em Heidegger. Revista Paradigma, 24(2), 43-56. Recuperado de: https://egov.ufsc.br/portal/sites/default/files/689-2748-2-pb.pdf. Acesso em: 22.05.2020.

Mello, C. M. (2017). O Fundamento do Direito em Heidegger. Lex Cult Revista do CCJF, 1(1), 50-60. DOI: https://doi.org/10.30749/2594-8261.v1n1p50-60

Mello, C. M. (2018a). Os Teoremas da Diferença Ontológica e do Círculo Hermenêutico em Heidegger. Poiesis - Revista de Filosofia, 16 (1), 26-39. Recuperado de: https:// www.periodicos.unimontes.br/index.php/poiesis/article/view/12. Acesso em: 20.05.2020.

Mello, C. M. (2018b). Hermenêutica e Direito - a hermenêutica de Heidegger na (re) fundamentação do mundo jurídico. $2^{\mathrm{a} e d}$. Rio de Janeiro, RJ: Ed. Processo.

a virada ontológica proposta por seu principal discípulo - Gadamer -, cujas investigações têm as raízes atreladas aos teoremas fundamentais da filosofia hermenêutica, a partir da qual é possível a superação do esquema sujeito-objeto que, historicamente, predomina no interior do pensamento jurídico, na medida em que este ainda oscila entre os paradigmas aristotélico-tomista (objetivista) e da filosofia da consciência (subjetivista)" (Trindade, 2017, p. 197). 
Mello, C. M.; Martins, V. (2016). Hermenêutica e Direito: o Dasein na filosofia hermenêutica de Heidegger. Revista Quaestio luris, 09(03), 1.443-1.451. Recuperado de: https://www.e-publicacoes.uerj.br/index.php/quaestioiuris/article/ viewFile/22201/17943. Acesso em: 23.05.2020.

Mora, J. F. (2001). Dicionário de Filosofia. Tradução de Roberto Leal Ferreira, Álvaro do Amaral. $4^{a}$ ed. São Paulo, SP: Martins Fontes.

Moraes, M. C. B. (1991). A caminho de um direito civil constitucional. Revista Direito, Estado e Sociedade, 01(01), 126-163. Recuperado de: https://revistades.jur.puc-rio.br/ index.php/revistades/index Acesso em: 23.05.2020.

Pereira, V. M. (2015). Sobre a tese "ser que pode ser compreendido é linguagem": hermenêutica como teoria filosófica. Cadernos de Filosofia Alemã, 20 (02), 157178. DOI: http://dx.doi.org/10.11606/issn.2318-9800.v20i2p157-178

Rocha, L. A. C. B. L. M.; Almeida, A. F. (2017). A dignidade da pessoa humana no direito a ser alguém - notas sobre a importância jurídica do sobrenome e sua transição para a tutela do direito à identidade. In: Pessôa, U.; Santos, L. \& Ciotola, M. (orgs.). O Neoconstitucionalismo à luz da sociedade contemporânea: desafios e perspectivas (pp. 181-202). Belo Horizonte, MG: Editar, p. 181-202.

Rodotà, S. (2008). A vida na sociedade da vigilância. Tradução de Maria Celina Bodin de Moraes. Rio de Janeiro, RJ: Renovar.

Sarmento, D. (2016). Dignidade da Pessoa Humana: Conteúdo, trajetórias e metodologia. $2^{\mathrm{a}}$ ed. Belo Horizonte, MG: Ed. Fórum.

Schreiber, A.; Navares, A. L. (2016). Do sujeito à pessoa: uma análise da incapacidade civil. In: Tepedino, G; Teixeira, A. C. B. \& Almeida, V. (orgs.) O Direito Civil entre o sujeito e a pessoa. (pp. 39-56). Belo Horizonte, MG: Fórum.

Sibillia, P. (2016). O show do eu: a intimidade como espetáculo. $2^{\mathrm{a}}$ ed. Rio de Janeiro, RJ: Contraponto.

Stein, E. (2014). Seis Estudos Sobre "Ser e Tempo". 5ªed. Petrópolis, RJ: Vozes.

Streck, L. (2014). Hermenêutica jurídica e(m) crise: uma exploração hermenêutica da construção do Direito. [Versão Kindle]. 11. ed. (virtual) rev., atual. e ampliada - Porto Alegre, RS: Livraria do Advogado Editora.

Tepedino, G. (2004). Temas de Direito Civil, v. I. $3^{\text {a }}$ ed. Rio de Janeiro, RJ: Renovar.

Trindade, A. K. (2017). As Bases Filosóficas da Crítica Hermenêutica do Direito. In: Alvim, E. A.; Leite, G. S.; Sarlet, I. W. \& Jr., N. N. (orgs.). Jurisdição e Hermenêutica Constitucional em homenagem a Lenio Streck (pp.191-210). Rio de Janeiro: Mundo Jurídico.

Welter, B. P. (2009). Teoria tridimensional do direito de família. Porto Alegre, RS: Livraria do Advogado.

Esta obra está licenciada com uma Licença Creative Commons Atribuição-NãoComercial-Compartilhalgual 4.0 Internacional.

https://creativecommons.org/licenses/by-nc-sa/4.0/

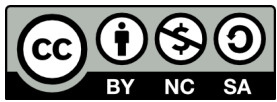

